\title{
The Definition of Scenarios for the CESARE-RISK Model
}

\author{
LONGDE ZHAO and VAUGHAN BECK
}

Centre for Environmental Safety and Risk Engineering

Victoria University of Technology

PO Box 14428, MCMC, Melbourne, Victoria 8001, Australia

\begin{abstract}
A cost-effective risk assessment model, CESARE-RISK, is being developed for residential buildings in Australia by the Centre for Environmental Safety and Risk Engineering (CESARE) at Victoria University of Technology (VUT). The model is being further developed with funds provided by the Fire Code Reform Centre Ltd (FCRC), Australia. CESARE has been appointed to lead the development of this model, with support from other Australian research organisations. This work uses the methodology developed by Beck and adopts the expected risk-to-life (ERL) and fire-cost expectation (FCE) parameters to appraise the risk and cost associated with the effects of fires in buildings. CESARERISK is a new model, which builds on previous work undertaken in Australia and elsewhere, has a number of new submodels which include fire spread model, detection and activation model, human behaviour model and expected number of deaths models. This paper describes some of the fire scenarios which are a central feature of the CESARE-RISK model.
\end{abstract}

KEYWORDS: Fire Safety, Risk Assessment, Fire Growth, Fire Spread, Human Behaviour, Dynamic Event Tree Structure, Expected Response Approach

\section{INTRODUCTION}

The Fire Code Reform Centre Ltd (FCRC) was established during 1994 as an independent organisation to operate on a national basis to undertake a major program of fire code reform. FCRC was formed as a co-joint initiative between the Australian Government, industry and research organisations. Its mission is to develop for approval and adoption by 
the Australian Building Codes Board (ABCB) a cost-effective engineered approach to fire safety design and reform aspects of the existing building code based on similar principles, and industry. $\mathrm{ABCB}$ is responsible for the Building Code of Australia (BCA) which forms the basis of all building regulations in Australia. As a result of one FCRC project, a Fire Engineering Guidelines (FEG) document [1] was published which provides guidance for design engineers, consultants and building approval officials to use as a basis for fire engineering building design. While the methodology described in FEG is in a text form, it is often desirable to have computer software as an additional tool which can help the design engineer, consultant or building official to identify cost-effective building design solutions. The CESARE-RISK model is designed to be such a tool. The initial application of the CESARE-RISK model for the FCRC will be to prescribe alternative fire safety system design solutions for inclusion in the BCA. These alternative design solutions will at least provide the same level of safety while being more cost-effective than the existing design solutions prescribed in the BCA by offering designers greater flexibility.

It has been a relatively common feature of fire engineering practice to evaluate a design based on a relatively few scenarios, and in some cases one scenario. Fires in buildings are essentially non-stationary stochastic processes, and thereby have an infinite number of realisations. Accordingly, the cost-effective design of a fire safety system based on, at most, a few representative scenarios, is considered either potentially dangerous (since some significant scenarios could be ignored), or at best conservative (in a limited number of cases) by invoking "worst case" conditions for analysis. The authors strongly advocate the need to evaluate a design based on the consideration of multiple scenarios. The challenge is to choose a sufficiently representative set of scenarios for analysis from a large population consistent with a desire to limit the inherent complexity and computational duration. Presented in this paper is a description of the authors attempt at producing such a representative set. Clearly more extensive set of scenarios could have been chosen.

\section{RISK ASSESSMENT METHODOLOGY}

The general methodology for building fire safety system design is

1. Determine the acceptance criteria

2. Identify hazards within the building

3. Propose a design to overcome the hazards

4. Select scenarios to test the design

5. Estimate the required parameters for the design.

6. Compare the outcome of the required parameters with the acceptance criteria, if satisfied, the design is acceptable. Otherwise propose another design, and repeat the analysis until the design criteria are satisfied.

Risk assessment has been conceptualised as a number of distinct and interrelated phases [2]. One of the risk assessment methods developed by Beck [3] uses two performance parameters, namely, the expected risk-to-life and fire-cost expectation, to appraise the risk and cost associated with fires in buildings. In the original model [4], a number of stochastic, state-transition submodels and interactive deterministic submodels were developed to represent the dynamic interaction between human behaviour and fire growth. Some of the submodels were replaced and further developed at National Research Council 
of Canada (NRCC). Subsequent research collaboration between VUT and the NRCC resulted in several publications under joint authorship [5, 6]. This research collaboration has been very beneficial in the sharing of ideas, concepts and results. As evidence of the evolutionary developments associated with the original risk-cost assessment model concept, the NRCC have published details of their FIRECAM ${ }^{\mathrm{TM}}$ risk cost-assessment model [7], whereas in Australia, related developments have led to the development of the CESARERISK model (described below).

\section{CURRENT RISK ASSESSMENT METHODOLOGY}

The CESARE-RISK model is based on the recognition that the modelling of fire growth and spread of fire in a building and its interaction with occupant egress can be split into two components. The first component of the modelling consists of establishing an event tree to describe the conditions of the building. Initially a static event tree is used to represent building conditions such as whether or not the doors are open. Then a dynamic event tree is used to represent the uncertainty of fire growth and spread. Given the occurrence of a particular scenario (a branch in the event tree), deterministic models are used to calculate the fire environment, occupant response and evacuation, and then the expected number of deaths. The expected risk-to-life for occupants in a given fire scenario is then determined by the life loss associated with that scenario multiplied by the probability of the scenario occurring. The overall expected risk-to-life from fires in a building is the sum of the expected life risks of all fire scenarios over the expected life of the building. Similarly, the total fire-cost expectation is the sum of all the investment in fire safety systems plus the expected property loss from fires in the building over the expected life of the building.

\section{GENERIC BUILDING LAYOUT}

This work considers generic types of residential buildings, since the output of the CESARE-RISK model will be used initially to identify alternative fire safety system design solutions for inclusion in the BCA. Typically such buildings consist of multiple apartment units per level, where each level can have a different floor layout. For simplicity, it was decided to consider a generic building layout in which such apartment buildings have two categories of floor-plan layout; namely: (a) the level of fire origin and (b) levels other than

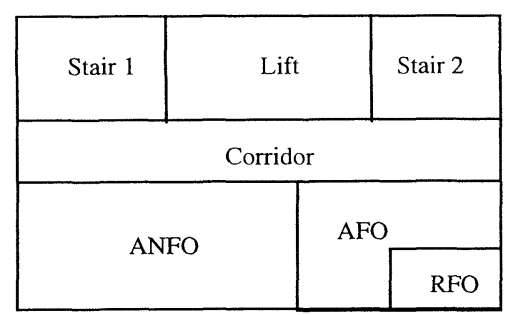

(a)

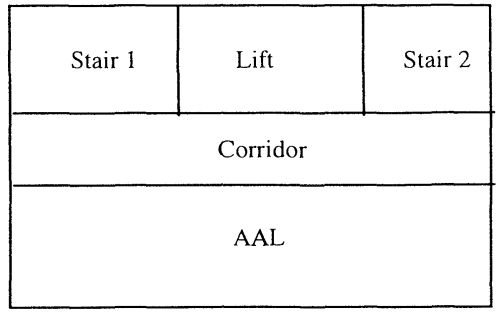

(b)

FIGURE 1 Generic Building Layout (a) Level of Fire Origin (b) Other Levels. 
the level of the fire origin, as shown in Figure 1. On the level of fire origin, it was further decided to consider two types of apartments; namely (a) the apartment of fire origin (AFO) and (b) the apartments of non-fire origin (ANFO). In recognition that many fires are confined within the room of fire origin (RFO), the room of fire origin is individually considered. On the levels other than the level of fire origin, it was decided for simplicity to represent each of the apartments as a single apartment, which is denoted as AAL.

\section{IMPORTANT FACTORS CONSIDERED IN THE CESARE-RISK MODEL}

There are many variables which can affect the fire safety of a building. To consider all of the factors, the number of scenarios will be effectively infinite. Thus the CESARE-RISK model only considers the most important factors which could significantly affect the number of lives lost. These important factors have been identified and are given in Table 1.

TABLE 1: Important Factors Considered in the CESARE-RISK Model

\begin{tabular}{|c|c|}
\hline Category & Factors \\
\hline Building Condition & $\begin{array}{l}\text { - Ventilation (door open/closed, air handling on/off, window } \\
\text { open/closed) } \\
\text { - Equipment operational performance (detector, sprinkler, } \\
\text { smoke management, stair pressurisation) } \\
\text { - Barrier performance (walls, doors, floors, windows) } \\
\text { - Constructional materials (steel, concrete, metal, wood) } \\
\text { - Fire fighting facilities }\end{array}$ \\
\hline Fire Starts & $\begin{array}{ll}\text { - } & \text { Ignition source } \\
\text { - } & \text { Location (kitchen, bedroom and lounge) } \\
\text { - } & \text { Type of fires (smouldering, flaming and flashover) }\end{array}$ \\
\hline Building Content & $\begin{array}{l}\text { - Rate of fire growth } \\
\text { - Fuel load density }\end{array}$ \\
\hline Occupant Profile & - Based on demographics (Australian Bureau of Statistics) \\
\hline Occupant Condition & $\begin{array}{ll}\text { - } & \text { Awake/Asleep } \\
\text { - } & \text { Drugs } \\
\text { - } & \text { Disabilities } \\
\end{array}$ \\
\hline Fire Brigade & $\begin{array}{ll}\text { - } & \text { Search and rescue } \\
\text { - } & \text { Fire Fighting } \\
\end{array}$ \\
\hline
\end{tabular}

In the present work, three types of fires are considered. However in reality, there are only two types of fire starts, smouldering and flaming. Smouldering fires are assumed to remain as smouldering fires during the fire development, and flaming fires can either remain as flaming fires or develop to flashover fires. Thus, it was decided to classify the flaming fire starts into two categories: flaming non-flashover and flaming potential flashover. The flaming non-flashover fires are assumed to remain as flaming fires, while the flaming potential flashover fires have the possibility to develop to flashover fires depending on various conditions such as door open/closed. 


\section{DYNAMIC STRUCTURE OF EVENT TREE FOR FIRE SCENARIOS}

Fire is essentially a stochastic process. For instance, the failure of a barrier will not be known until the fire is simulated, while in turn, the failure of the barrier may have an effect on the fire growth. A time-dependent barrier failure model being developed by Clancy et al. [8] is used to predict the probability and time of barrier failure. In an attempt to reflect the inherent nature of the stochastic process, a dynamic structure is used to represent the event tree for fire scenarios; that is, where the event tree changes with the failure of barriers and/or fire spread.

For smouldering fires and flaming non-flashover fires, it is assumed that there will be no fire spread (of any consequence) from the room of fire origin; therefore, the event tree for the fire scenario is static. For flaming/flashover fires, the event tree for the fire scenarios can change because of fire spread. The latter aspect will be detailed in this paper.

The initial fire scenarios for flaming/flashover fires are the same as for smouldering fires and flaming non-flashover fires shown in Figure 2, in which six scenarios are defined:

1. All doors open

2. RFO door open, $\mathrm{AFO}$ door open, stair 1 door open, stair 2 door closed

3. RFO door open, AFO door open, stair 1 door closed, stair 2 door open

4. RFO door open, AFO door open, two stair doors closed

5. RFO door open, $\mathrm{AFO}$ door closed

6. RFO door closed

The probabilities for the above six scenarios are respectively:

1. $P_{\text {RFOIDO }} \times P_{A F O / D O} \times P_{S 1 / D O} \times P_{S 2 / D O}$,

2. $P_{R F O / D O} \times P_{A F O / D O} \times P_{S 1 / D O} \times\left(1-P_{S 2 / D O}\right)$

3. $P_{R F O / D O} \times P_{A F O I D O} \times\left(1-P_{S I / D O}\right) \times P_{S 2 / D O}$

4. $P_{\text {RFOIDO }} \times P_{A F O / D O} \times\left(1-P_{S 1 / D O}\right) \times\left(1-P_{S 2 / D O}\right)$

5. $P_{R F O / D O} \times\left(1-P_{A F O / D O}\right)$

6. 1-P $P_{R F O / D O}$, where subscript DO denotes door open.

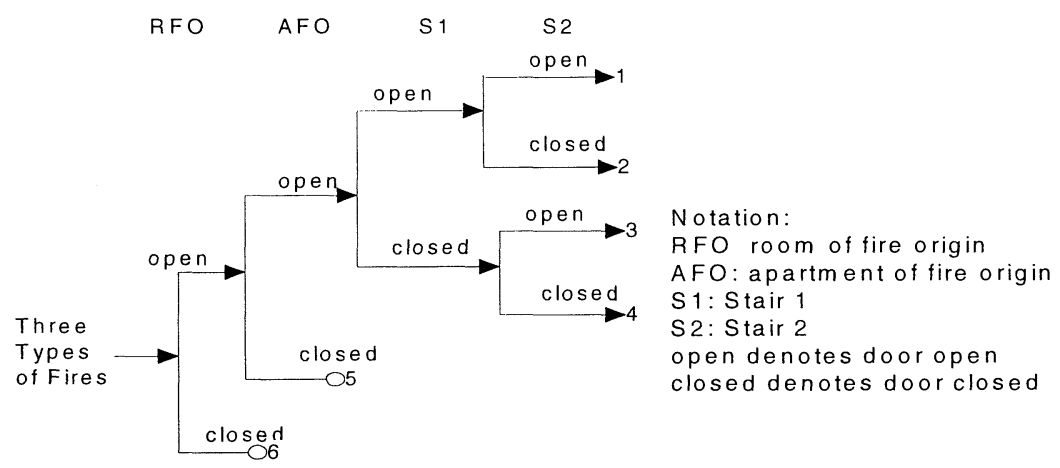

FIGURE 2 Event Tree if There Is No Fire Spread beyond the Room of Fire Origin 
In cases of fire spread or barrier failure, there will be some additional scenarios which need to be considered. For instance, if the door of the room of fire origin fails, then the fire scenarios that need to be considered should be as shown in Figure 3, where BF denotes the barrier failure, and NBF denotes the barrier has not failed. The failure of the RFO door and the spread of fire to AFO will not be known until the initial fire scenarios shown in Figure 2 have been considered. Thus a dynamic structure of the event tree for the definition of fire scenarios is required, that is, the initial fire scenarios as shown in Figure 2 are considered first, then modifications or additions are considered. In this case, additional fire scenarios are required for fire spread to AFO as shown in Figure 3. In Figure 3, there are five cases in Block A when fire spread to AFO occurs. Generally, fires which can cause door failure are flashover fires, thus it is assumed that if the door has failed, fire will spread out of the room of fire origin. Accordingly, as shown in Figure 3, for the case of RFO door failure, there are also five cases as in Block $\mathrm{A}$.

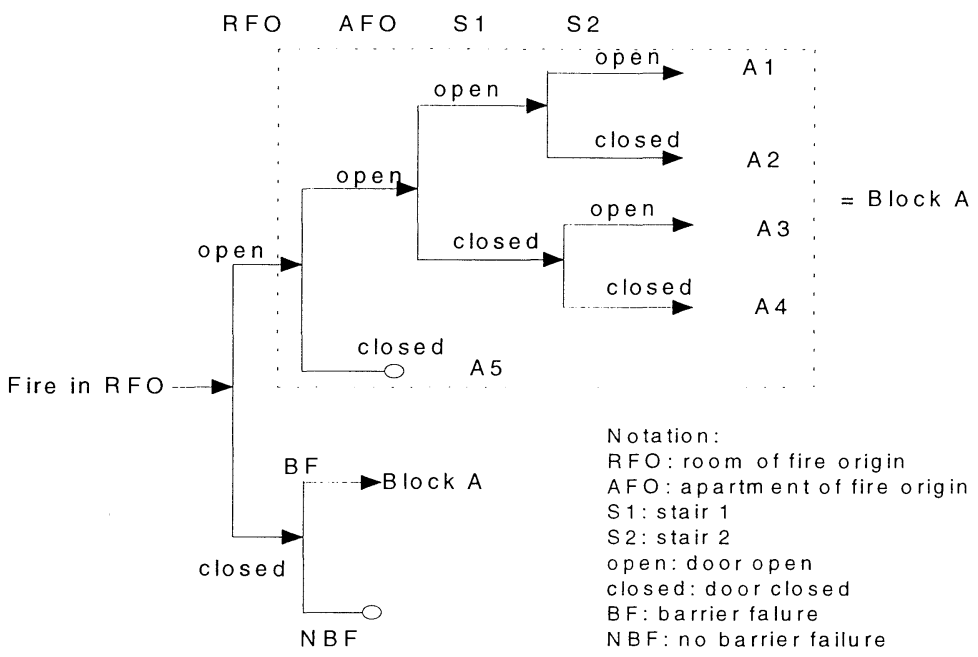

FIGURE 3 Event Tree for the Case of Fire Spread from RFO to AFO

If fire spread to AFO occurs in the case of RFO door being open, or after the failure of RFO door, two fires will exist at the same time, namely in RFO and AFO. Because of the limitation of the existing fire growth model, fire growth for multiple fires can not be modelled at the same time. Hence, it is proposed that a simple additive approach is used; that is, the two fires are assumed to be independent in terms of fire growth but where the exhaust conditions are combined.

If a fire is initiated in AFO, failure of the horizontal and vertical barriers will be considered. These barriers will be arranged according to their times of barrier failure, which are predicted by the Barrier Failure Model [8]. If a barrier does not fail, the time of barrier failure is assumed to be infinity. The barrier failure in AFO can be illustrated as shown in 
Figure 4. For the case of the AFO door open, the horizontal barrier and the vertical barrier are arranged according to their times of barrier failure; these are denoted as barrier A and B in descending order of time of barrier failure. For the case of for the case of the AFO door closed, the AFO door, the horizontal barrier and the vertical barrier are also arranged according to their times of barrier failure; these are denoted as barrier 1,2 and 3 in descending order of time of barrier failure.

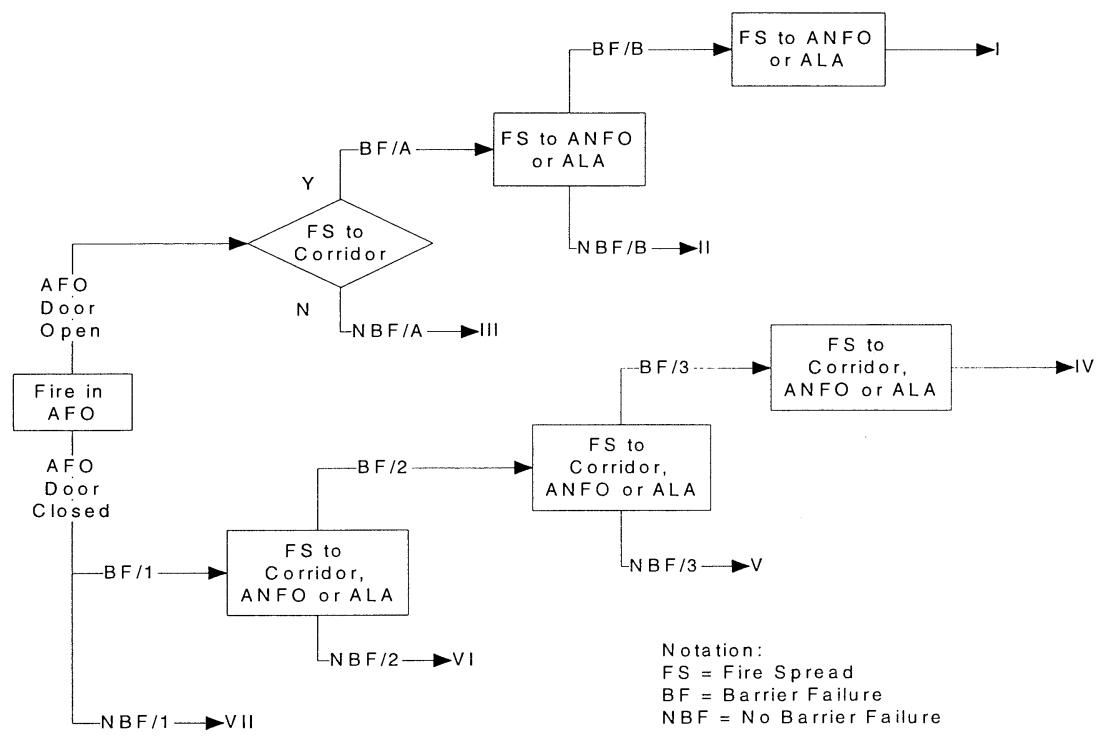

FIGURE 4 Event Tree for the Fire Spread out of the Apartment of Fire Origin

As shown in Figure 4, for the case of AFO door being open, three resultant fire scenarios can be defined as (1) no barriers fail, (2) one barrier fails and the other does not fail, and (3) both barriers fail. Thus for those fire scenarios having AFO door open as shown in Figure 3, each scenario may become three different scenarios if fire spread to AFO occurs, namely I to III in Figure 4. If barrier $\mathrm{A}$ is the wall between AFO and ANFO, when it fails, fire spread to ANFO occurs; and if barrier A is the floor between AFO and ALA, or windows of AFO and ALA, when it fails, fire spread to ALA occurs. Similarly, if the AFO door is closed, there will be four scenarios, namely, (1) no barriers fail, (2) one barrier fails, the other two do not fail, (3) two barriers fail, the other does not fail, and (4) all the three barriers fail. These are shown as IV to VII in Figure 4. Whether the events shown in Figure 4 occur or not will not be known until the fire growth model is run for the fires in RFO and AFO. Thus, to properly represent this dynamic nature of fire spread, the CESARE-RISK model uses dynamic event trees. That is, it uses the event tree shown in Figure 2 to define the initial fire scenarios, Figure 3 to define the scenarios when fire spread to AFO occurs in case of RFO door failure, and a combination of Figure 4 and Figure 3 to represent the fire scenarios when fire spread from $\mathrm{AFO}$ to its adjoining enclosures occurs. 
Following the definition of the fire scenarios (described previously), the time-dependent fire environment throughout the building is predicted. To incorporate the distributional effect of independent variables, such as fuel load, on the severity of the fire, the CESARE-RISK model uses a three-realisation method [9] for the apartment of fire origin. With this method, three realisations of fire severity are selected for each of the three fire types and their relevant fire scenarios in the apartment of fire origin. Each of the fire severity selections is used as input to deterministic models that predict the time-dependent fire environment. For the remainder of the building, the mean value for fire severity is used to predict fire and smoke spread. This approach has been adopted because the fire environment in the apartment of fire origin is expected to have the most significant effect on fire fatalities and also because expected loss parameters are used as indicators of performance.

\section{AN EXPECTED RESPONSE APPROACH FOR HUMAN BEHAVIOUR}

The purpose of the Human Behaviour Model in the evaluation of risk-to-life is to estimate the expected number of occupants and their condition in each location as a function of time. The conditions of occupants are defined to be either stationary, ambulatory, incapacitation or fatality. The latter two conditions are determined by accumulating the toxic and thermal dose of occupants as a function of the time-dependent fire environment in the building. In the case of the apartment of fire origin, the problem can be represented by an event tree as shown in Figure 5, in which two fire cues are considered, and the occupants are assumed to act as a group; that is, it is assumed that the occupants of an apartment either all leave or all stay. Fire cues could be the sight of flames, the smell of smoke, sound of an alarm, communication by others and so on. Each fire cue has a probability and a time of occurrence, which are denoted as Pcue and tcue respectively. The perception of the cue by the occupants is probabilistic, and if the occupants receive the cue, the occupants' decision to evacuate their apartments is also probabilistic. The process of both perception and decision to evacuate has a probability of Pevac and occurs at a time to commence evacuation, tevac, which equals tcue $+\Delta t$, where $\Delta t$ denotes the response duration.

As has been noted previously, one of the problems with the event-tree method is that the number of scenarios increases dramatically as the number of events is increased. An attempt has been made herein to reduce the total number of scenarios for the human behaviour model without the introduction of significant errors. The three realisation method [9], used for the fire growth scenarios, is used also for the response of the occupants in the apartment of fire origin. For a given realisation for the fire severity random variable, the time of detection is a random variable and the occupant response duration to that cue is also a random variable. Thus the time to commence evacuation is a random variable. Three values are taken from each distribution for the following variables: fire severity, occupant tenability limits, time of fire brigade arrival and time to commence evacuation. Hence, there are $27 \times 3^{n}$ combinations of realisations for each scenario, where $n$ is the number of cues that result in evacuation. While the probability of detector activation and the probability of occupant response to cues are random variables, then for the purpose of convenience, only one realisation for each variable is used. A sensitivity study will be conducted to investigate the effect of variations of these probabilities on the expected number of deaths. 
A simple illustrative example is given in this section for the calculation of the expected number of deaths in the apartment of fire origin. For the apartment of fire origin, the time of untenable conditions is assumed to be also the time at which occupants reach a fatality condition. To determine the number of fatalities, the number of occupants who respond to the fire cue and decide to evacuate and leave their apartment after a certain time delay is very important. For convenience, the calculation using only one combination of realisations for occupant response scenarios will be detailed. In this example, there are two cues occurring at tcue 1 with a probability of Pcuel and tcue 2 with a probability of Pcue2 respectively as shown in Figure 5. At the time of tevac1, the number of occupants undertaking evacuation is $\mathrm{N}$ having a probability of $\mathrm{P} 1$ (=Pcue $1 \times \mathrm{Pevac} 1)$. At the time of tevac2, the number of occupants undertaking evacuation is $\mathrm{N}$ having a probability of (1$\mathrm{P} 1) \times \mathrm{P} 2$, where $\mathrm{P} 2=\mathrm{Pcue} 2 \times \mathrm{Pevac} 2$. Thus, the expected number of occupants in the evacuation process is $\mathrm{N} \times \mathrm{P} 1$ at the time of tevac1, and $\mathrm{N} \times(1-\mathrm{P} 1) \times \mathrm{P} 2$ at the time of tevac2. Hence there are $\mathrm{N} \times[1-\mathrm{P} 1-(1-\mathrm{P} 1) \times \mathrm{P} 2]$ occupants who will not be evacuated. All of these outcomes happen in seven different scenarios. The expected response approach considers only one scenario in which (1) $\mathrm{N} \times \mathrm{P} 1$ are evacuated at the time of tevac 1, (2) $\mathrm{N} \times(1-\mathrm{P} 1) \times \mathrm{P} 2$ are evacuated at the time of tevac2; and (3) $\mathrm{N} \times[1-\mathrm{P} 1-(1-\mathrm{P} 1) \times \mathrm{P} 2]$ are not evacuated. If there are $\mathrm{n}$ cues, the expected number of occupants remaining in their apartments at $i$ th evacuation time is $\mathrm{N}_{\mathrm{i}}$ :

$N_{i}=N_{i-1} \times\left(1-P_{i}\right)$

where $P_{i}=$ Pcue $_{i} \times P_{\text {evac }}$. It is assumed, for simplicity, that failure of occupants to respond to a given cue does not alter the probability of responding to the later cues. A comparison of using the full event tree and the expected response approach for the calculation of the expected number of deaths is given below.

Suppose that there are 6 people in an apartment, and there are two cues occurring at 60 seconds and 180 seconds respectively, which have a probability of occurrence of 0.4 and 0.95 respectively. The probability of occupants response to the first cue is 0.5 , and that to the second is 0.9 . The time delay for the occupants to commence evacuation after receiving a cue is 80 seconds. The expected number of deaths for a scenario is the number of fatalities for the scenario times the probability of the scenario. In the calculation of the expected number of deaths, it is assumed that occupants will die after the time of untenable conditions, and not die before the time of untenable conditions. Assume that the time of untenable conditions for one combination of realisations (for fire severity and tenability limits) occurs somewhere in the range of $140<\mathrm{t}<260 \mathrm{~s}$, and using the full event-tree analysis which considers three scenarios as shown in Figure 5, then the expected numbers of deaths are:
(a) 0 ,
(b) $1.2\{=6 \times$ Pcue $1 \times(1-$ Pevac 1$)=6 \times 0.2\}$,
(c) $3.6\{=6 \times(1-$ Pcue 1$)=6 \times 0.6\}$,

It should be noted that no evacuation can occur after the time of untenable conditions since the occupants are assumed to have died; hence, the occupants do not respond to the second cue. The total expected number of deaths is 4.8. Using the expected response approach, the 
number of occupants remaining in the apartment is calculated using equation (1), that is $6 \times(1-0.4 \times 0.5)=4.8$. This value, which is also the expected number of deaths, is the same as that obtained using the event tree analysis.

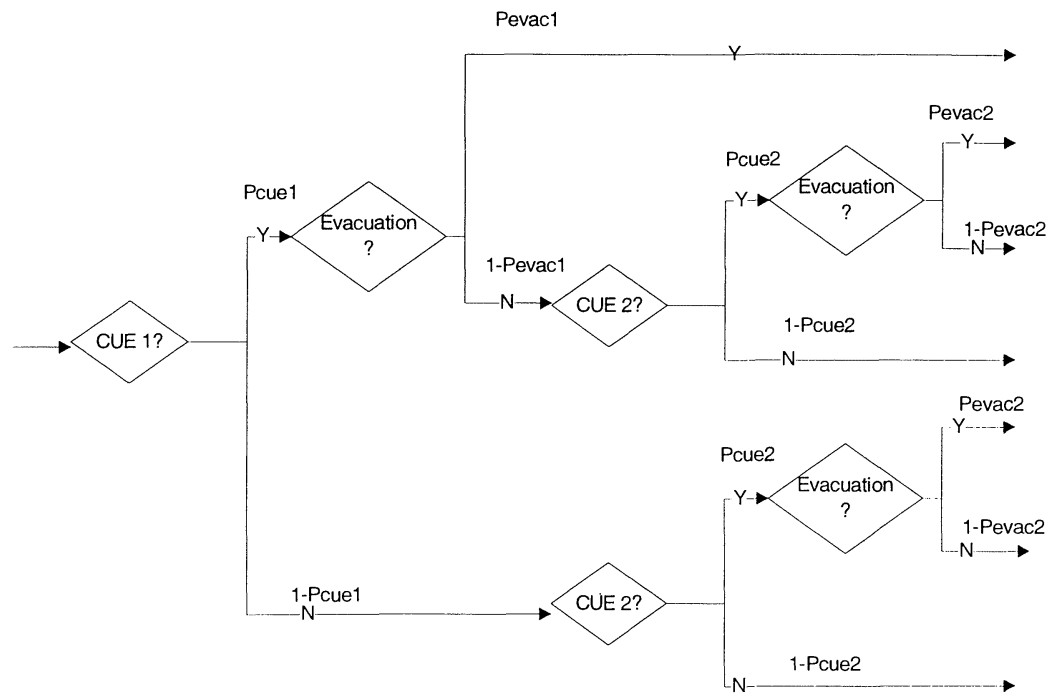

FIGURE 5 Event Tree for Occupant Response and Evacuation for Two Fire Cues

If the time of untenable conditions for one combination of realisations (for fire severity and tenability limits) occurs at $t>260 \mathrm{~s}$, and using the full event-tree analysis which considers seven scenarios as shown in Figure 5, the expected numbers of deaths are:

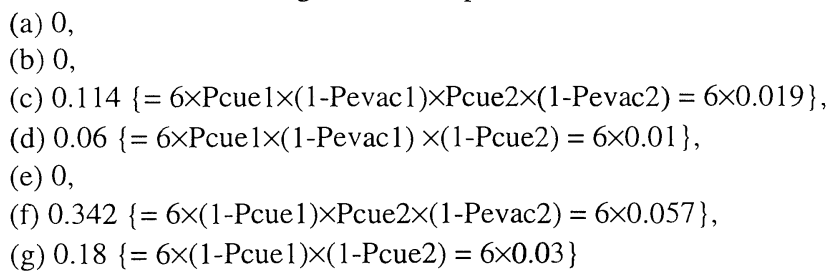

The total expected number of deaths is 0.696 . Using the expected response approach, the expected number of occupants remaining in the apartment using equation (1) is $4.8 \times(1$ $0.9 \times 0.95)=0.696$; this is also the expected number of deaths. The calculated result using the expected response approach is the same as that obtained using the event tree analysis. The number of occupants remaining in the enclosure is shown in Figure 6 for one combination of realisations for occupant response to cues.

The advantage of using this expected response approach is that the number of human behaviour scenarios is always one irrespective of the number of cues considered. For the apartment of fire origin, there are $3^{\mathrm{n}}$ combinations of realisations for one human behaviour 
scenario, where $\mathrm{n}$ is the number of cues that result in evacuation. It should be noted that the expected number of occupants in the evacuation process may be a fraction, which will be kept as a fraction in the Human Behaviour Model. This approach is consistent with the risk assessment methodology where the expected number of deaths is sought. The expected number of deaths for one scenario in the apartment of fire origin is the average of the expected number of deaths for each combination of realisations attached to that scenario.

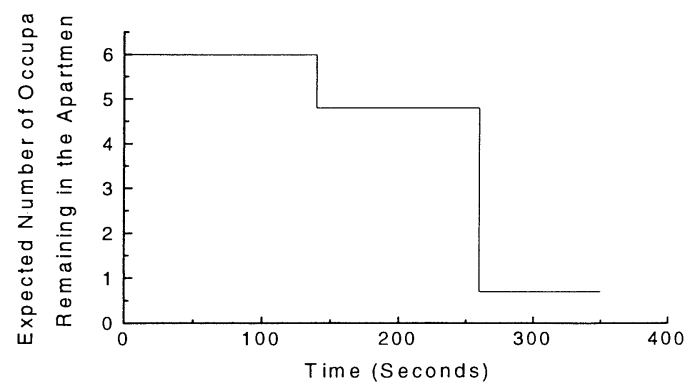

FIGURE 6 Expected Number of Occupants Remaining in the Apartment of Fire Origin

\section{CONCLUSIONS}

The CESARE-RISK model is a risk-cost assessment model which is used to identify costeffective design solutions for building fire safety systems. The model is used to estimate the expected performance of a design and two performance parameters, namely, the expected risk-to-life and fire-cost expectation, are used to appraise the risk and cost associated with that design. This paper describes the definition of a set of representative scenarios for the evaluation of a design.

A dynamic structure for event trees is used to represent the stochastic process associated with the development of fires. An expected response approach for human behaviour is also proposed. The advantage of this approach is that the total number of human behaviour scenarios is reduced to one for a given fire growth scenario. Nevertheless, for each scenario, there are multiple combinations of realisations for fire severity, occupant response to cues and occupant tenability limits. Thus the total number of fire growth, fire spread and human behaviour scenarios and combinations of realisations is large, ranging from hundreds to thousands. However, the overall computational time can be reduced significantly compared with that using the Monte Carlo method while still retaining reasonable accuracy. Further, the calculation procedure for the expected number of deaths using the expected response approach is consistent with the overall approach adopted for the risk-cost assessment model.

Future work is required to determine whether the set of scenarios and combinations of realisations described in this paper can be used to represent the large number of outcomes resulting from fires in buildings. 


\section{ACKNOWLEDGMENTS}

The work reported herein has been funded, in part, by the Fire Code Reform Centre (FCRC) Ltd, Australia. As part of the FCRC program, the authors have received valuable suggestions from Dr. I. Thomas and Mr. L. Poon of BHP Research - Melbourne Laboratory and Mr. Moore of Scientific Service Laboratory. The authors are also grateful for other useful discussions with Dr. D. Yung and Dr. G. Hadjisophocleous of the National Research Council of Canada.

\section{REFERENCES}

1. Fire Engineering Guidelines, Fire Code Reform Centre, Sydney, Australia, 1996.

2. Rowe, W. D., "Risk Assessment and Methods", Society Technology and Risk Assessment, edited by Conrad, J., Academic Press, London, pp. 3-30, 1980.

3. Beck, V. R., "Cost-Effective Fire Safety and Protection Design Requirements for Buildings", Ph.D. Thesis, School of Building, University of New South Wales, July, 1986.

4. Beck, V. R., "A Cost-Effective, Decision-Making Model for Building Fire Safety and Protection", Fire Safety Journal, Vol. 12, pp. 121-138, 1987.

5. Yung, D. and Beck, V.R., "Building Fire Safety Risk Analysis", Society of Fire Protection Engineers, Handbook of Fire Protection Engineering, National Fire Protection Association, Quincy, Massachusetts, USA, Chapter 5, pp. 95-101, June 1995.

6. Beck, V.R., Yung, D., He, Y. and Sumathipala, K., "Experimental Validation of a Fire Growth Model", Proceedings of 7th International Fire Science and Engineering Conference, Interflam'95, 26-28 March, Cambridge, Interscience Communications, London, pp. 653-662, 1995.

7. Yung, D., Hadjisophocleous, G. V. and Proulx G., "Modelling Concepts for the RiskCost Assessment Model FIRECAM ${ }^{\mathrm{TM}}$ and Its Application to a Canadian Government Office Building", Proceedings of the Fifth International Symposium on Fire Safety Science, Melbourne, Australia, Hasemi, Y. (Editor), International Association for Fire Safety Science, 1997 (to be published).

8. Clancy, P., Young, S. A., Beck, V. R. and Leicester, R. H., "Modelling of Timber Framed Barriers in Real Fires", Pacific Timber Engineering Conference, Gold Coast Australia, Vol 2, pp. 282-293, July 1994.

9. Beck V. R., "Performance-Based fire engineering design and its application in Australia", Proceedings of the Fifth International Symposium on Fire Safety Science, Melbourne, Australia, Hasemi, Y. (Editor), International Association for Fire Safety Science, 1997 (to be published). 